Journal of

Strategic Management

(JSM)

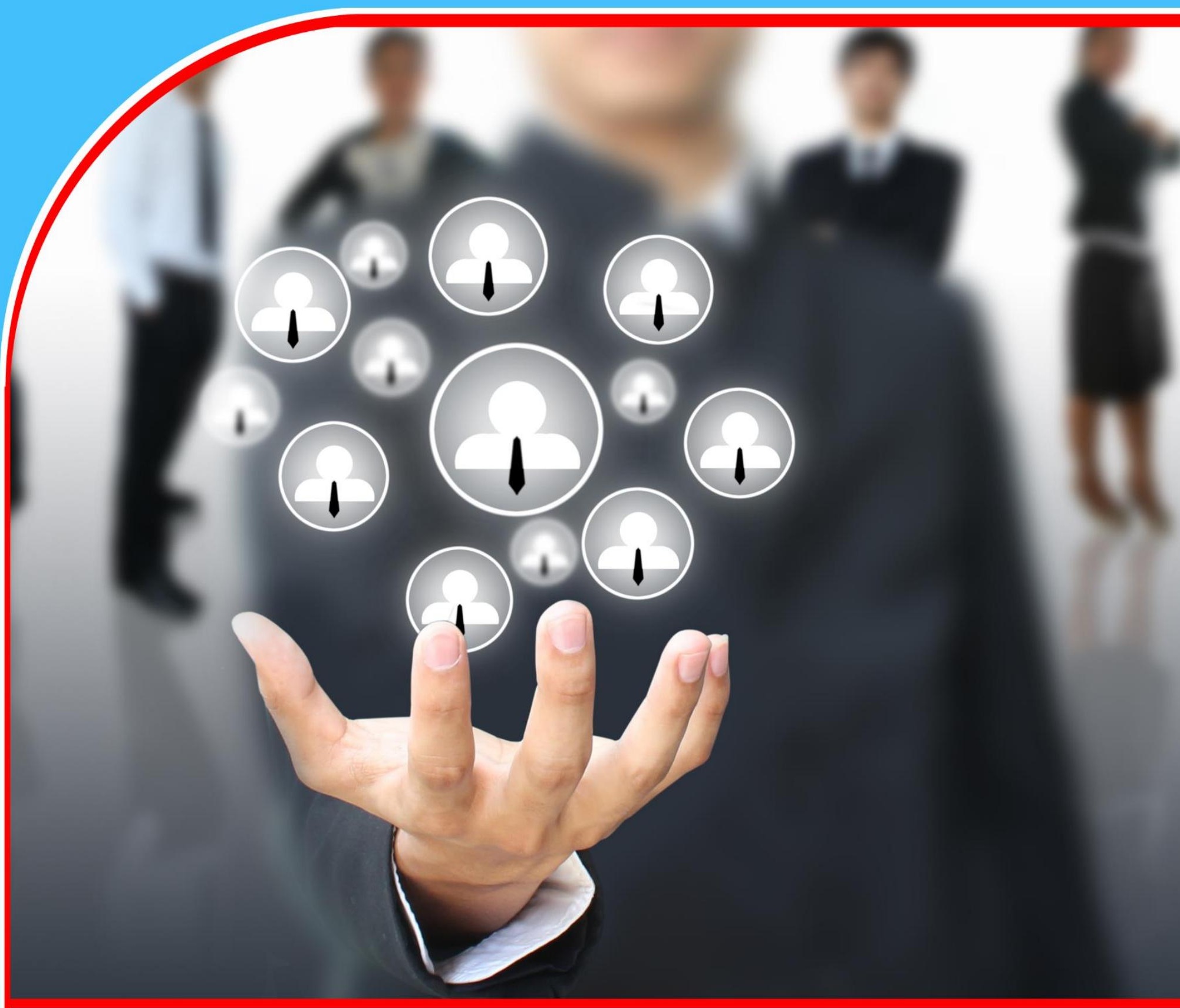

ORGANIZATIONAL TRUSTWORTHINESS AND

EMPLOYEE INNOVATIVE WORK BEHAVIOUR

Tamunomiebi Miebaka Dagogo PhD

Adoki Edmund Barasin

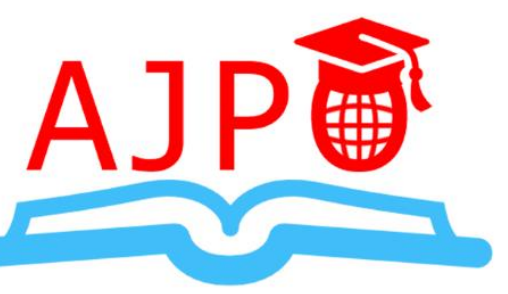




\title{
ORGANIZATIONAL TRUSTWORTHINESS AND EMPLOYEE INNOVATIVE WORK BEHAVIOUR
}

\author{
${ }^{1}$ Tamunomiebi Miebaka Dagogo PhD \\ ${ }^{1}$ Department of Management, Faculty of Management Sciences, Rivers, State University, \\ Nkpolu-Oroworukwo, PMB 5080, Port Harcourt, Nigeria. \\ ${ }^{2}$ Adoki Edmund Barasin \\ ${ }^{2}$ Doctoral Candidate Department of Management, Faculty of Management Sciences, Rivers \\ State University, Nkpolu-Oroworukwo, PMB 5080, Port Harcourt, Nigeria.
}

\begin{abstract}
Purpose: The purpose of this paper was to examine the relationship between organizational trustworthiness and employee innovative work behaviour.

Methodology: The paper is designed as a theoretical paper and as such discusses related theories which conceptualize and detail the relationship between the variables. The content of the paper addressed the nature and implications of organizational trustworthiness for employee innovative work behaviour by offering insight on issues which bother on employee work expectations, as well as the relationship between managers/supervisors and their employees.

Findings: It was stated that there is the need for organizations to emphasis on practices and qualities which express their substantial levels of benevolence, integrity and competence as a way of enhancing their trustworthiness and as such, increasing employee innovative behaviour within the workplace.

Unique Contribution to Practice and Policy: The management should focus on developing work structures that are transparent and which allow for active participation and involvement; such that actions and decisions by the leadership can be justified on the basis of competency and integrity, thus boosting the confidence of employees in the organization.
\end{abstract}

Keywords: Organizational Trustworthiness, Employee Innovative Work Behaviour, Trust, Competency, Integrity, Benevolence, Creativity 


\section{INTRODUCTION}

Nowadays, the importance of employee innovative work behaviour for desired organizational outcomes and wellbeing is widely accepted (Yuan \& Woodman, 2010). Employee's capacity for creativity and innovativeness as expressed within the organization is vital and imperative for the wellbeing and functionality of both private (de Jong \& den Hartog, 2010) as well as the public sector (Bartos, 2003; Breul \& Kamensky, 2008; Walker \& Damanpour, 2008). The growing interest in employee innovative work behaviour stems primarily from the need to remain competitive and as such can be considered as having both strategic as well as functional implications for the organization.

In general, employee innovative work behaviour studies have dealt with the expressions of creativity and innovativeness by the employees or workers within the framework of the organization (King \& Anderson, 2002). This includes conditions concerned with determining several practices, mechanisms and factors stimulating or inhibiting the expressions of creativity, originality, uniqueness and exceptionality. Employee innovative work behaviour (IWB), which is described as the development, adoption and implementation of new ideas by the employees for products, technologies and work methods by employees (Yuan \& Woodman, 2010).

The imperatives of employee innovative work behaviour are premised on the fact that the origin as well as the consumption of innovation lies with individuals, causing individuals' actions to be of crucial importance for the continuous improvement of business processes and products (Janssen, 2000). This assumption is generally drawn not only in the academic literature on innovativeness, but is also found in the domains of total quality management (McLouglin \& Harris, 1997) and corporate entrepreneurship (Sharma \& Chrisman, 1999)

Several factors have been studied as stimulators or barriers towards employee innovative work behaviour including organization culture and climate (Scott \& Bruce, 1994), the interaction between subordinates and supervisors (Janssen \& Van Yperen, 2004), job characteristics (Oldham \& Cummings, 1996), social group context (Munton \& West, 1995), as well as individual differences and intermediate psychological processes that explain how different individual and contextual antecedents affect innovative behaviour (Yuan \& Woodman, 2010). Examples of such psychological processes are an individual's intrinsic interest in his or her task (Amabile, 1996; Woodman et al., 1993) and expected payoffs (Far \& Ford, 1990).

These studies have led to the development and assessment of several conceptual models meant to predict relationships between such factors and employee innovative behaviour (Farr \& Ford, 1990; Yuan \& Woodman, 2010). Scholars studying the process of employee innovative work behaviour within the public sector noted that innovative work behaviour is likely to be restrained by more barriers and to a larger extend in the public sector than in the private sector (Rainey \& Bozeman, 2001; Rainey, 2009).

Several issues, or barriers, contribute to the fact that within the public sector, the success and effectiveness of initiatives meant to foster employee innovative behaviour can be inhibited. One of those barriers is the fact that in general, public firms lack competitive pressures vis-àvis private firms ( Verhoest et al., 2007), taking away an important trigger towards managers and policy-makers to stimulate the innovativeness of, and IWB within, their firm. This is as employee's perceptions about top management may subsequently become realigned with the 
motivation to express dissatisfactory attitudes based on their distrust of the organization (Agnieszka \& Dariusz, 2016; Braun et al., 2013).

According to Joe (2014), employees' perception of top management as trustworthy is vital for facilitating the development and diffusion of innovative ideas within the workforce. Pay, Balaji and Kok (2015) postulate that a major factor that also influences employees' willingness to share their innovative ideas is their trustworthiness perception of their leaders and of the organization itself. In this case, the diffusion of innovative ideas may very well depend on top managements' ability, benevolence and integrity to engage in interpersonal relationships that can help to engender employee innovative work behaviour (Rebecca \& David, 2015).

In this vein, the success and substantiality of employee innovative work behaviour are often built on trustworthiness perceptions that then determine the emergence or continuity of trust relationships, and invariable expressions of innovation. Trustworthiness is an important factor that facilitates an employee's decision-making process to become vulnerable to organisational top management leaders (Vathsala \& Ruvini, 2012). It further promotes employee's commitment and engagement towards employee innovative initiatives (Jan \& Hazel, 2013). According to Upasna (2014), it is important for top management and employees to develop, and maintain a strong trust relationship in order to sustain positive organisational impact on employee innovative work behaviour. As such this paper discussed the role of organizational trustworthiness in stimulating employee innovative work behaviour.

\section{LITERATURE REVIEW}

\section{Theoretical Foundation (Leader-Member Exchange)}

The leader-member exchange theory propounded by Dansereau et al., 1975; Graen \& Cashman, 1975 is adopted as the theoretical framework in this study. The theory describes the relationship between leaders and their subordinates in a manner that identifies the imperatives of recognition, support and empowerment in the development of trust-based relationships (Hodson, 2004). The leader-member exchange theory is a form of the social exchange theory which advances the need for stronger levels of cooperation and collaboration between leaders and their subordinates (Hardin, 2002). This paper therefore adopts the leader-exchange theory as a foundation in describing the features of leadership and the manner of its relationship with subordinates that drive improved work behaviour and employee outcomes such as innovative work behaviour.

\section{The Concept of Trust}

Trust is a trans-disciplinary construct that has been used in psychology, sociology, economics, political science, and marketing to study different types of relationships (Ben-Rechav, 2000; Mayer, James \& Schoorman, 1995). In marketing, it has been an important component in a significant research stream focusing on employer-employee and organization-customer relationships (Ganesan \& Hess, 1997) as well as in services area where a customer does not have an opportunity to evaluate the service prior to its use (Dovaliene, Gadeikiene \& Piligrimiene, 2007).

There is no agreed-upon definition of trust in the literature. There are probably as many definitions as there are authors on the subject. A quick review of the literature found over ten definitions of trust (Wang and Huff, 2007). In spite of this diversity, however, a common thread cuts across all definitions. Trust refers to a mutual confidence that no party to an exchange will 
exploit another's vulnerabilities (Sabel, 1993; Huff, 2005). As such, it alleviates the uncertainty inherent in an exchange relationship. At its core, trust reflects reliability and confidence in the exchange party to fulfil its obligation in a way that leads to positive outcomes. In the services sector, the intangibility and high risk involved in service transactions means that the concept of trust is even more crucial in developing and maintaining business relationships. Trust is a multidimensional phenomenon. In a study of the relationship between the organization and its employees, Heffernan et al. (2008) identified three dimensions of trust: credibility, integrity and benevolence. They found a positive and significant relationship between the dimensions of trust, relationship manager's level of trust, emotional intelligence and organizational financial performance.

Wong, Cheung and Ho (2005) identified four underlying factors in successful partnering between developers and consultant groups: performance, permeability, system-based trust and relational bonding. Dovalieno, Gadeikieno and Piligrimieno (2007) analysed the role of trust as an antecedent of long-term customer relationship. The researchers conducted an empirical study on odontology services to identify the determinants of customers' trust and the relationship between the various determinants and the overall level of trust. The researchers found that trust plays a key role in determining the behavioural intentions of customers to pursue a long-term relationship (intentions to visit the same deontologist again and intentions to recommend) with the service provider. In subsequent analysis they found strong correlations between trust and satisfaction, outcome quality and customization.

A strong positive correlation was also found between trust and its determinants and behavioural intentions. Finally, a multiple linear regression was carried out to determine the presence of linear relationship between trust and its determinants. Here, only satisfaction emerged as a significant variable in explaining the variance in trust whereas the quality dimensions and communications were not significant. Ndubisi and Wah (2005) conducted an empirical study to examine the relationship between perceived quality of bank-customer relationship and customer satisfaction in the Malaysian banking industry. The key underpinnings of the relationship identified in this study were trust, commitment, competence, communication and conflict handling.

\section{The Concept of Organizational Trustworthiness}

While trust is an attribute of the relationship between exchange partners, trustworthiness is an attribute of the individuals involved in the exchange. An exchange partner is trustworthy if he or she does not exploit the vulnerabilities of the other exchange partner (Barney \& Hansen 1994; Huff 2005). The way the construct of trustworthiness has been conceptualized in the literature is not very clear cut. Much of the literature on trust hardly mentions trustworthiness, even though implicitly much of it is primarily about trustworthiness, not about trust (Hardin 2002).

Where the construct has been explicitly conceptualized, its conceptualization has primarily revolved around perceived qualities or attributes of an exchange partner that leads the partner to act in the interest of the other partner (Mayer et al. 1995; Hodson, 2004). As such, trustworthiness is belief-based and accumulates over time as a result of repeated experiences (Buttner \& Goritz, 2008; Caldwell \& Clapham, 2003; Caldwell \& Jeffries, 2001). Given the subjective nature of trustworthiness it is not surprising to note that two individuals may have very different views about who they can trust. 
Lee and Turban (2001) identified integrity, competency, ability and benevolence as the underlying dimensions of organizational trustworthiness. These dimensions were later confirmed by Chong et al. (2003) in a study of e-commerce organizations. In a study by Caldwell and Clapham (2003) ability and skills, competencies and expertise emerged as the key elements of organizational trustworthiness. Similarly, Bews and Rossouw (2002) found openness, integrity, benevolence, and competency as the dimensions of organizational trustworthiness in insurance service provider.

Mayer et al. (1995) espoused that organizational trustworthiness, moderated by the employee's propensity to trust relates a willingness to trust. However, when trust is established, the organization and the employee are bound by a system of shared values (Lipponen, Bardi, \& Haapamaki, 2008) to initiate the risk of achieving a desired outcome (Ann-Marie et al., 2015). These shared values are thus integrated values expressed through the interpersonal trust relationship that exists and are reflected in defined organisational cultures (Cameron, 2008; Carlos \& Maria, 2014). Thus, organizational trustworthiness is that vital part of organisational members' lives which influences the relationship between the organisational culture and employee sense of trust (Colquitt \& Rodell, 2011; Rawlins, 2008; Shalley \& Gilson, 2004).

\section{Employee Innovative Work Behaviour}

Innovation theory states that innovativeness is broader than only creativity and also includes the implementation of ideas (King \& Anderson, 2002). Thus, Innovative Work Behaviour (IWB) does not only include idea generation, but also behaviours needed to implement ideas and achieve improvements that will enhance personal and/or business performance. Following Farr and Ford (1990) we define innovative work behaviour as an individual's behaviour that aims to achieve the initiation and intentional introduction (within a work role, group or organization) of new and useful ideas, processes, products or procedures.

The measure of IWB developed here thus captures both the initiation and implementation of creative ideas. The construct of IWB is closely related to employee creativity. Creativity is defined as the production of new and useful ideas concerning products, services, processes and procedures (Oldham \& Cummings, 1996).

However, some differences between the constructs exist (West \& Farr, 1990; Scott \& Bruce, 1994). Unlike creativity IWB is explicitly intended to provide some kind of benefit. It has a clearer applied component and is expected to result in innovative output. Creativity can be seen as a crucial component of IWB, most evident in the beginning of the innovation process, when problems or performance gaps are recognized and ideas are generated in response to a perceived need for innovation (West, 2002).

Despite the differences between IWB and creativity, the overlap is clear and the application processes has also started to receive attention in the creativity literature. For example, in his review of creativity research, Mumford (2003) calls for the investigation of so-called 'late cycle' skills, that is, the implementation of creative ideas. He stresses that realworld performance the expression, shaping and execution of ideas - represents 'another important component of creative work and considers the investigation of implementing ideas to be an important emerging issue for creativity research. Similarly, Basadur (2004) included 'solution implementation' in his model of leading the creative process. The distinction between IWB and creativity thus seems to be one of emphasis rather than substance. 
More recent measures of IWB distinguish between various dimensions, which are often linked to different stages of the innovation process. For example, Scott and Bruce (1994) operationalized IWB as a multistage process. Drawing on Kanter (1988), Scott and Bruce (1994 outline three stages relevant to IWB, namely idea generation, coalition building and implementation. Individual innovation begins with problem recognition and the generation of ideas or solutions, either novel or adopted. Next, an innovative individual seeks sponsorship for an idea and through coalition building tries to gain support for it. Finally, the innovative individual contributes to idea implementation, for example, by producing a prototype or model of the innovation or working on the execution of the idea in other ways. Of the three forms of innovative behaviour Scott and Bruce (1994) distinguish, idea generation is rather broad as it includes both generating ideas and the recognition of problems (Scott \& Bruce, 1994). Several creativity studies indicate that these two behaviours rely on distinct cognitive abilities (Runco \& Chand, 1994).

\section{Organizational Trustworthiness and Employee Innovative Work Behaviour}

Pay, et al (2015) espouse that organizational trustworthiness is a major bedrock on which interpersonal relationships involving trust can be built. Trustworthiness is thus expedient to foster the fruition and diffusion of innovative ideas among employees (Ghosh, 2015; Liu et al., 2016). Employees that perceive organizational as not trustworthy enough or even untrustworthy, may not be willing to exhibit certain creative or innovative behaviours. This may consequently limit the extent at which employee creativity may be engendered within an organisation. Nevertheless, Amabile et al. (1996) and Amabile and Mueller (2008) further opine that employee innovative work behaviour should reflect its highest degree when an intrinsically motivated employee with high expertise and high creativity skills exhibit creative behaviours within a highly supportive organisational culture.

According to Pay et al. (2015), literature on trust recognizes the concept of trustworthiness as a critical component of social and interpersonal interaction, although, its definition and measurement are yet to be consistent. This is because the concept of trustworthiness is complex in that it is clustered with issues surrounding its definition and measurement (Carlos \& Maria, 2014). Likewise, studies conducted over 50 years ago relate several trustworthiness dimensions which creates a pattern in regards to trustworthiness definitions and measurements (Rawlins, 2008). Nevertheless, the concept of trustworthiness yet proves to be imperative for the effective diffusion of creative ideas (Carlos \& Maria, 2014). Trustworthiness is necessary for the continuous development and maintenance of interpersonal relationships between the manager and the employee. It is an indispensable element of satisfactory relationship which reassures the organization about increasing commitment towards employee creativity and innovativeness (Carlos \& Maria, 2014).

Organizational trustworthiness plays several roles. Even in positively impacting the organisational culture by facilitating transparency and openness in communication between organisational members (Liu et al., 2016). Studies argue that trustworthiness could be characterized by integrity, just personality and fairness, dependability, reliability, and competence (Colquitt \& Rodell, 2011; Liu et al., 2016). Similarly, trustworthiness makes it less difficult for an employee to commit willingly and sincerely towards self-openness. For this to occur in most cases, the employee must have been able to prove an acceptable degree of integrity, dependability, reliability, honesty, commitment and acts of goodwill (Morrow et al., 
2004). Although, through cognitive submission processes the employee may become vulnerable and dependent on the choices of another employee (Liu et al., 2016).

Correspondingly, the effect of organizational trustworthiness in interpersonal trust relationships is a key instrument of organizational co-ordination and control (Carlos \& Maria, 2014). This is in view that it facilitates employee commitment to engage in employee creativity initiatives. Employee creativity initiatives in this regard could be a program tailored towards the effective and efficient diffusion of creative ideas within the organisation (Carlos \& Maria, 2014). Upasna (2014) also support that employee innovativeness involves the risk of employee participation in decision making processes, thus mistakes are inevitable. This could often be the outcome when perceived trustworthiness levels of organisational members are high. Another probable outcome could be an experience of employees' freedom of action as well as employees trusting their managers towards engagement and support in employee creativity initiatives (Carlos \& Maria, 2014).

\section{CONCLUSION}

The theories and the discussion of literature offered in this paper, identify the imperatives of trust in the context of the relationship between the organization and its workers. The views expressed as well as the theories assessed offer a supportive framework which advance the importance of organizational trustworthiness in the actualization of employee innovative work behaviour. As noted in the discussion, particular reference is made to the need for workers to identify the organization as possessing certain qualities and features (e.g. benevolence, integrity etc.) which as specified in the study, are considered as imperative in enhancing their confidence in the organization and also in driving their desire to be more innovative in their work behaviour and actions. In conclusion, this paper therefore affirms that there is the need for organizations to emphasis on practices and qualities which express their substantial levels of benevolence, integrity and competence as a way of enhancing their trustworthiness and as such, increasing employee innovative behaviour within the workplace.

\section{RECOMMENDATIONS}

In view of the conclusions reached, the following recommendations are put forward:

i. Management should focus on developing work structures that are transparent and which allow for active participation and involvement; such that actions and decisions by the leadership are can be justified on the basis of competency and integrity, thus boosting the confidence of employees in the organization.

ii. Work designs should be such that offer the necessary support and conditions for consistent communication and correspondence between managers/supervisors and their subordinates. Such designs should be enriched with delegated roles that allow for the increased responsibilities on the employee as a way of expressing confidence in their own capacities.

iii. Learning platforms and programs within the organization should be developed to enable workers within the organization acquaint themselves with the particular skills and exposure necessary in driving innovative work. This is also linked to workers considerations of support from management for the development and consistency of such programs 


\section{REFERENCES}

Agnieszka, W.-T., \& Dariusz, T. (2016). The significance of perceived social organization climate for creating employees' innovativeness. Management Research Review, 39(2), $167-195$.

Amabile, T. M., \& Mueller, J. S. (2008). Studying creativity, its processes, and its antecedents: An exploration of the componential theory of creativity. In J. Zhou, \& C. E. Shalley, Handbook of organizational creativity, 33- 64. New York: Lawrence Erlbaum Associates.

Amabile, T. M., Hill, K. G., Hennessey, B. A., \& Tighe, E. M. (1994). The work preference inventory: Assessing intrinsic and extrinsic motivational orientations. Journal of Personality and Social Psychology, 66(5), 950-967.

Ann-Marie, N., Philipp, D. R., Rosalind, S., \& Gerhard, S. (2015). A qualitative meta-analysis of trust in supervisor-subordinate relationships. Journal of Managerial Psychology, $30(5), 507-534$.

Barney, J. \& M. Hansen (1994). Trustworthiness as a source of competitive advantage, Strategic Management Journal, 15,175-190.

Bartos, S. (2003). Creating and sustaining innovation. Australian Journal of Public Administration, 62(1), 09-14.

Ben-Rechav, GilaGabay (2000).Relationship selling and trust: Antecedents and outcomes, Ph.D. dissertation, Portland State University.

Bews, N.F. and G. J. Rossouw (2002). The role of business ethics in facilitating trustworthiness. Journal of Business Ethics, 39(4), 377-389.

Braun, S., Peus, C., Weisweiler, S., \& Frey, D. (2013). Transformational leadership, job satisfaction, and team performance: A multilevel mediation model of trust. The Leadership Quarterly, 24(1), 270-283.

Breul, J.D. \& Kamensky, J.M. (2008) Federal government reform: Lessons from Clinton's “Reinventing Government and Bush's Management Agenda initiatives. Public Administration Review 68, 1009-1026.

Buttner, O. B. \& A. S. Goritz (2008). Perceived trustworthiness of online shops, Journal of Consumer Behaviour, 7(1), 35-50.

Caldwell, C. \& F. L. Jeffries (2001). Ethics, norms, dispositional trust, and context: components of the missing link between trustworthiness and trust, paper presented at Eight Annual Conference on Ethics in Business, DePaul University, Chicago, IL

Caldwell, C. \& S. E. Clapham (2003). Organisational trustworthiness: An international perspective, Journal of Business Ethics, 47(4), 349-364.

Cameron, K. (2008). A process for changing organizational culture. In C. G. Thomas, Handbook of organizational developmenT. Thousand Oaks, CA: Sage Publishing.

Carlos, F. P., \& Maria, F. S. (2014). Knowledge-centred culture and knowledge sharing: the moderator role of trust propensity. Journal of Knowledge Management, 18(3), 538 - 550. 
Chong, B., Z. Yang and M. Wong (2003). Asymmetrical impact of trustworthiness attributes on trust, perceived value and purchase intention: A conceptual framework for crosscultural study on consumer perception of online auction, proceedings at $A C M$ International Conference Proceeding Series; 50, Pittsburgh, Pennsylvania, 213 - 219.

Colquitt, J. A., \& Rodell, B. J. (2011). Justice, trust, and trustworthiness: A longitudinal analysis integrating three theoretical perspectives. Academy of Management Journal, 54(6), 1183-1206.

De Jong, J., \& Den Hartog, D. (2010). Measuring innovative work behaviour. Creativity and Innovation Management, 19(1), 23-36.

Farr, J. L., \& Ford, C. M. (1990) Individual innovation. In M. A. West \& J. L. Farr (Eds.), Innovation and creativity at work: Psychological and organizational strategies: 63- 80. Chichester, U.K.: Wiley

Ganesan, S. \& Hess, R. (1997). Dimensions and levels of trust: Implications for commitment to a relationship, Marketing Letters, 8(4), 439-448.

Ghosh, K. (2015). Developing organizational creativity and innovation. Management Research Review, 38(11), 1126 - 1148.

Hardin, R. (2002).Trust and trustworthiness. New York: Russell Sage Foundation Series on Trust.

Heffernan T., G. O'Neill G., T. Travaglione \& M. Droulers (2008). Relationship marketing the impact of emotional intelligence and trust on bank performance, International Journal of Bank Marketing, 26(3), 183-199.

Hodson, R. (2004). Organizational trustworthiness: Findings from the population of organizational ethnographies, Organization Science, 15(4), 432-445.

Huff, L. C. (2005). Stages in the development of customers, trust for services providers, Asia Pacific Advances in Consumer Research,6, 105-110.

Jan, A., \& Hazel, H. (2013). Organisational culture in knowledge creation, creativity and innovation: towards the Freiraum model. Journal of Information Science, 1-14

Janssen, O. (2000) Job demands, perceptions of effort-reward fairness, and innovative work behaviour. Journal of Occupational and Organizational Psychology, 73, 287-302.

Janssen, O., \& Van Yperen, N. W. (2004). Employees' goal orientations, the quality of leadermember exchange, and the outcomes of job performance and job satisfaction. Academy of Management Journal, 47: 368-384.

Joe, K. (2014). Do my staff trust me? Leadership \& Organization Development Journal, 35(5), $470-488$.

Kanter, R. M. (1983). The change masters: Innovation and entrepreneurship in the American Corporation. Touchstone Book.

King, N. and Anderson, N. (2002).Managing innovation and change: A critical guide for organizations. Thomson, London. 
Lee, Matthew K. \& Efraim Turban (2001). A trust model of consumer internet shopping, International Journal of Electronic Commerce, 6(1), 75-92.

Lipponen, J., Bardi, A., \& Haapamaki, J. (2008). The interaction between values and organizational identification in predicting suggestion-making at work. Journal of Occupational and Organizational Psychology, 81, 241-248.

Liu, W., Zhang, P., Liao, J., Hao, P., \& Mao, J. (2016). Abusive supervision and employee creativity: The mediating role of psychological safety and organizational identification. Management Decision, 54(1), 130 - 147.

Mayer, R. C., H. D. James \& F. D. Schoorman (1995). An integrative model of organizational trust. Academy of Management Review, 20(3), 709-734

McLoughlin, I. \& Harris, M. (1997) Innovation, organizational change and technology. Thompson, London.

Mumford, M. D., \& Gustafson, S. B. (1988). Creativity syndrome: Integration, application, and innovation. Psychological Bulletin, 103(1), 27

Munton, A. G., \& West, M. A. (1995) Innovations and personal change: Patterns of adjustment to relocation. Journal of Organizational Behaviour, 16: 363-375.

Ndubisi, N.O. \& C. K. Wah (2005). Factorial and discriminant analyses of the underpinnings of relationship marketing and customer satisfaction, International Journal of Bank Management, 23(7), 542-557.

Oldham, G. R., \& Cummings, A. (1996) Employee creativity: Personal and contextual factors at work. Academy of Management Journal, 39, 607-634.

Pay, L. Y., Balaji, M. S., \& Kok, W. K. (2015). Building trust in internet banking: A trustworthiness Perspective. Industrial Management \& Data Systems, 115(2), 235 - 252.

Rainey, H. G., \& Bozeman, B. (2000) Comparing public and private organizations: Empirical research and the power of the a priori. Journal of Public Administration Research and Theory 10, 447-69.

Rainey, H.G. (2009) Understanding and managing public organizations, 4th ed. San Francisco, CA: Jossey-Bass.

Rawlins, B. R. (2008). Measuring the relationship between organizational transparency and employee trust. Public Relations Journal, 2(2), 1-21.

Rebecca, A. R., \& David, S. (2015). Facilitating tacit knowledge transfer: routine compatibility, trustworthiness, and integration in M \& As. Journal of Knowledge Management, 19(2), 257 - 276.

Runco, M. A., Plucker, J. A., \& Lim, W. (2001). Development and psychometric integrity of a measure of ideational behaviour. Creativity Research Journal, 13(3-4), 393-400.

Sabel C. F. (1993). Studied trust: Building new forms of cooperation in a volatile economy, Human Relations, 46(9), 1133-1170. 
Scott, S.G. \& Bruce, R.A. (1994) Determinants of innovative behaviour: A Path Model of Individual Innovation in the Workplace. Academy of Management Journal, 38, 1442-65.

Shalley, C. E., \& Gilson, L. L. (2004). What leaders need to know: A review of social and contextual factors that can foster or hinder creativity. The Leadership Quarterly, 15, 3353.

Sharma, P. \& Chrisman, J.J. (1999) Toward a reconciliation of the definitional issues in the field of corporate entrepreneurship. Entrepreneurship Theory and Practice, 23, 11-27.

Upasna, A. A. (2014). Linking justice, trust and innovative work behaviour to work engagement. Personnel Review, 43(1), 41 - 73.

Vathsala, W., \& Ruvini, W. (2012). Effects of interpersonal trust, team leader support, rewards, and knowledge sharing mechanisms on knowledge sharing in project teams. VINE, 42(2), $214-236$.

Verhoest, K. (2002). Resultaatgerichtverzelfstandigen: Een analyse vanuiteenverruimdprincipaal-agent perspectief. KUL. Nieuwe reeks van doctoraten in de socialewetenschappen, 70.

Walker, R.M. \& Damanpour, F. (2008). Innovation type and organizational performance: An empirical exploration. In Managing improvement in public service delivery: Progress and prospects, ed. C. Donaldson, J. Hartley, C. Skelcher, and M. Wallace. Cambridge: Cambridge Univ. Press.

Wang, S. \& Huff, L. C. (2007). Explaining buyers responses to sellers violation of trust, European Journal of Marketing, 41(9/10), 1033-1052.

West, M. A. (2002). Sparkling fountains or stagnant ponds: an integrative model of creativity and innovation implementation in work groups. Applied Psychology: An International Review, 51(3), 355-424.

West, M. A., \& Farr, J. L. (1989). Innovation at work: Psychological perspectives. Social Behaviour.

Wong, P. S. P., Cheung, S. O. \& Ho, P. K. M. (2005). Contractor as Trust Initiator in Construction Partnering - Prisoners Dilemma Perspective, Journal of Construction Engineering and Management, 131(10), 1045-1053.

Woodman, R. W., Sawyer, J. E., \& Griffin, R. W. (1993) Toward a theory of organizational creativity. Academy of Management Review, 18: 293-321.

Yuan, F., \& Woodman, R. W. (2010). Innovative behaviour in the workplace: The role of performance and image outcome expectations. Academy of Management Journal, 53(2), 323-342. 